\section{SAT0199 POLYAUTOIMMUNITY IN SYSTEMIC LUPUS ERYTHEMATOSUS. DATA FROM A LARGE SPANISH COHORT: SPANISH SOCIETY OF RHEUMATOLOGY REGISTRY OF PATIENTS WITH SYSTEMIC LUPUS ERYTHEMATOSUS (RELESSER).}

Natalia Mena-Vázquez ${ }^{1}$, Antonio Fernandez-Nebro ${ }^{1}$, Iñigo Rúa-Figueroa ${ }^{2}$, María Galindo-Izquierdo ${ }^{3}$, Juan Ovalles ${ }^{4}$, Alejandro Olivé ${ }^{5}$, Jaime Calvo ${ }^{6}$, Raúl Menor-Almagro ${ }^{7}$, Eva Tomero Muriel ${ }^{8}$, Esther Uriarte Isacelaya ${ }^{9}$, Alina Boteanu ${ }^{10}$, Mariano Andres ${ }^{11}$, Mercedes Freire González ${ }^{12}$, J. Narváez ${ }^{13}$, Tomas Vazquez Rodriguez ${ }^{14}$, Ricardo Blanco $0^{15}$, José A. Hernandez Beriain ${ }^{16}$, Jesus Ibañez ${ }^{17}$, Enrique Raya ${ }^{18}$, Joan Calvet ${ }^{19}$,Jose M. Pego-Reigosa ${ }^{20} .{ }^{1}$ UGC Reumatología, Instituto de Investigación biomédica de Málaga (IBIMA), Hospital Regional Universitario de Málaga, Universidad de Málaga, Málaga, Spain, ${ }^{2}$ Hospital Universitario Doctor Negrín., Las Palmas de Gran Canaria., Spain, ${ }^{3}$ Hospital Universitario 12 de Octubre, Madrid, Spain, ${ }^{4}$ Hospital Universitario Gregorio Marañón, Madrid, Spain, ${ }^{5}$ Hospital GermansTrias i Pujol, Barcelona., Spain, ${ }^{6}$ Hospital Universitario Araba., Vitoria., Spain, ${ }^{7}$ Hospital General Jerez de la Frontera., Cádiz, Spain, ${ }^{8}$ Hospital Universitario La princesa, Madrid, Spain, ${ }^{9}$ Hospital Universitario de Donosti, San Sebastián, Spain, ${ }^{10}$ Hospital Universitario Ramón y Cajal, Madrid, Spain, ${ }^{11}$ Hospital Parc Taulí, Sabadell, Spain, ${ }^{12}$ Complexo Hospitalario Universitario de A Coruña, Coruña, Spain, ${ }^{13}$ Servicio de Reumatología. Hospital Universitario de Bellvitge, Barcelona, Spain, ${ }^{14}$ Hospital Augusti, Lugo, Spain, ${ }^{15}$ Hospital Universitario Marqués de Valdecilla, Santander, Spain, ${ }^{16}$ Hospital Insular de Canarias, Las Palmas de Gran Canaria, Spain,

${ }^{17}$ Hospital Povisa, Vigo., Spain, ${ }^{18} \mathrm{Hospital}$ San Cecilio, Granada, Spain, ${ }^{19} \mathrm{Hospital}$ Parc Taulí, Barcelona., Spain, ${ }^{20}$ Complexo Hospitalario Universitario de Vigo, Pontevedra, Spain

\section{Background:}

Objectives: Estimate the frequency of the association of SLE with other autoimmune diseases in a large Spanish cohort of patients with systemic lupus erythematosus (SLE)

Methods:

Design: RELESSER is a nationwide multicentre, hospital-based registry of SLE patients. This is a cross-sectional study. Patients: Unselected consecutive adult patients with SLE, classified according to the ACR 1997 criteria. Main outcome: Polyautoimmunity was defined as patients who fulfilled criteria for SLE and other autoimmune disease: autoimmune thyroiditis, rheumatoid arthritis, systemic sclerosis or inflammatory myopathy and mixed connective tissue disease. Multiple autoimmune syndrome (MAS) was defined as patients who meet SLE criteria and at least two other autoimmune diseases. Statistical analysis: Descriptive. Multiple logistic regression analysis to investigate the possible risk factors for polyautoimmunity in patients with SLE.

Results: From 3679 (91.4\%) patients included in the registry, 501 $(13.6 \%)$ had Polyautoimmunity. The characteristics are showed in Table. The most frequent polyautoimmunity types associated with SLE were: autoimmune thyroiditis $(7.5 \%)$, other connective tissue disorders $(7.1 \%)$. Other autoimmune diseases not considered within the scope of Polyautoimmunity was $12.8 \%$ for Sjögren's syndrome and $12.7 \%$ for antiphospholipid syndrome. A family history of SLE was $12.4 \%$ and MAS in $10.2 \%$. The multivariate analysis identified age (odds ratio $[95 \% \mathrm{Cl}], 1.01$ [1.00-1.02]), sex (3.00 [1.48-6.04]), Raynaud's phenomenon (1.79 [1.342.39]), pulmonary fibrosis (2.88 [1.32-6.30]), Ro-La autoantibodies (1.68 [1.20-2.36]), antiRNP (1.79 [1.32-2.42]) and treatment with methotrexate (1.54 [1.08-2.18]) or with antimalarials $(0.57$ [0.41-0.78]) as factors associated with polyautoimmunity.

Conclusion: SLE patients associated poliautoimmunity in $14 \%$, MAS in $2 \%$. More studies are needed to better understand the increase of polyautoimmunity in these patients.

\begin{tabular}{|l|c}
\hline Variable & polyautoimmunity, (n=501) \\
\hline Sex (female), n (\%) & $473(94.4)$ \\
\hline Age $>50$ years, $\mathbf{n}(\%)$ & $134(15.4)$ \\
\hline Raynaud's phenomenon, $\mathbf{n}(\%)$ & $226(45.8)$ \\
\hline Lupus Nephritis, $\mathbf{n}(\%)$ & $131(26.5)$ \\
\hline Pulmonary fibrosis, n (\%) & $25(5.0)$ \\
\hline ANA+, $\mathbf{n}(\%)$ & $497(99.0)$ \\
\hline Anti-RNP, n (\%) & $164(34.1)$ \\
\hline Methotrexate, n (\%) & $120(24.7)$ \\
\hline Hydroxychloroquine, $\mathbf{n}(\%)$ & $369(76.7)$ \\
\hline
\end{tabular}

Disclosure of Interests: Natalia Mena-Vázquez: None declared, Antonio Fernandez-Nebro: None declared, Iñigo Rúa-Figueroa: None declared, María Galindo-Izquierdo: None declared, Juan Ovalles: None declared,
Alejandro Olivé Grant/research support from: ND, Consultant for: ND, Paid instructor for: ND, Speakers bureau: ND, Jaime Calvo Consultant for: Bristol-Myers Squibb, Janssen, Celgene, Sanofi Genzyme, Speakers bureau: Bristol-Myers Squibb, Raúl Menor-Almagro: None declared, Eva Tomero Muriel: None declared, Esther Uriarte Isacelaya: None declared, Alina Boteanu: None declared, Mariano Andres: None declared, Mercedes Freire González: None declared, J. Narváez Consultant for: Bristol-Myers Squibb, Tomas Vazquez Rodriguez: None declared, Ricardo Blanco: None declared, José A Hernandez Beriain: None declared, Jesus Ibañez: None declared, Enrique Raya: None declared, Joan Calvet: None declared, Jose M Pego-Reigosa: None declared DOI: 10.1136/annrheumdis-2019-eular.2876

\section{SAT0200 UNUSUAL SYSTEMIC LUPUS ERYTHEMATOSUS/ SJOEGREN'S SYNDROME PHENOTYPE IN A PATIENT WITH A TNFAIP3 GENE MUTATION}

Kerstin Nott ${ }^{* 1}$, Yvonne Glackin ${ }^{1}$,Stephen D. Marks ${ }^{2}$, Paul Brogan ${ }^{3}$, Sandrine Compeyrot-Lacassagne ${ }^{1}{ }^{1}$ Great Ormond Street Hospital, Rheumatology, London, United Kingdom, ; ${ }^{2}$ Great Ormond Street Hospital, Renal Unit, London, United Kingdom; ${ }^{3}$ University College London Great Ormond Street Institute of Child Health, Infection, Inflammation and Rheumatology Section, London, United Kingdom

Background: Mono-allelic mutation in tumor necrosis factor alpha induced protein 3 (TNFAIP3) has been found to cause haploinsufficiency of A2O protein, the cause of an early-onset auto inflammatory disease resembling Behcets's disease (BD). Single nucleotide polymorphism in TNFAIP3 may also contribute to susceptibility to systemic lupus erythematosus (SLE). Several mutations in TNFA1P3 have been shown to be disease-causing, including a single case with heterozygous mutation in the TNFAIP3 gene for $c .811 \mathrm{C}>\mathrm{T} ; \mathrm{p} .\left(\arg 271^{*}\right)$ with a BD-like phenotype.

Objectives: To report the case of a child with heterozygous mutation TNFAIP3 (c.811C>T; p. (arg271*) with an unusual SLE/SS (Sjoegren syndrome) phenotype, thus expanding the phenotype associated with this mutation; and describe the disease course and treatment

Methods: Clinical details were retrospectively collated using routine clinical records. The molecular cause of the phenotype was investigated using a targeted gene next generation sequencing (NGS) panel (the vasculitis and inflammation panel, VIP). Confirmation of findings detected by NGS were confirmed using conventional Sanger sequencing in the index case and subsequently in the parents.

Results: A 4yr old Caucasian female presented with a 2-year history of photosensitive malar rash, mouth ulcers, hair loss, arthralgia, livedo reticularis, cervical lymphadenopathy and hepatosplenomegaly. Laboratory tests revealed anemia, raised inflammatory markers and hypocomplementemia; RF, ANA and anti Ro positivity, raised C1q antibodies and low C1Q level. 7 out of 11 classification criteria for SLE were met and treatment with hydroxychloroquine was commenced.

Subsequently she developed blepharitis, acute anterior uveitis, chilblains and discoid skin lesions. Azathioprine and oral steroids were added.

Due to young age at disease onset, NGS screening was performed and revealed heterozygous mutation in TNFAIP3 c.811C>T; p.(Arg271*), Screening of both parents revealed the same mutation in the mother, who is asymptomatic. The child further developed Raynaud's and underwent renal biopsy for intermittent proteinuria which revealed ISN/RPS Class III and V lupus nephritis. Azathioprine was switched to mycophenolate mofetil. One year later her skin symptoms continue to improve, uveitis is in remission and her renal function is normal. Prednisolone was tapered off.

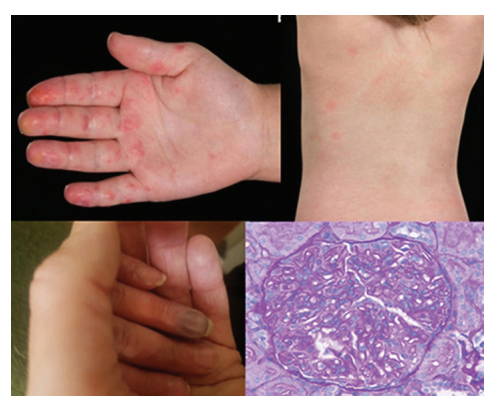

Figure: chilblain and discoid skin lesions, Raynaud's and histopathological changes from a renal biopsy consistent with glomerulonephritis 
Conclusion: We further expand the phenotype associated with mutation in the TNFAIP3; the c.811C>T; p. $\left(\arg 271^{*}\right)$ variant previously described as the cause of a BD-like-phenotype, in our case caused an auto immune disease with severe SLE/SS phenotype. This variant also demonstrated variable penetrance in our pedigree, since the mother harbours the same variant but remains asymptomatic. Thus, the genetic cause of monogenic lupus continues to expand, and the distinction between autoinflammatory and autoimmune disease is less clear-cut than first thought. REFERENCES:

[1] Aeschlimann, F. A., \& Laxer, R. M. (2018). Haploinsufficiency of A20 and other paediatric inflammatory disorders with mucosal involvement. Curr Opin Rheumatol, 30(5), 506-513

[2] Liu, X., Qin, H., Wu, J., \& Xu, J. (2018). Association of TNFAIP3 and TNIP1 polymorphisms with systemic lupus erythematosus risk: A metaanalysis. Gene, 668, 155-165

[3] Zhou, Q., Wang, H., Schwartz, D. M., Stoffels, M., Park, Y. H., Zhang, Y., Aksentijevich, I. (2016). Loss-of-function mutations in TNFAIP3 leading to A20 haploinsufficiency cause an early-onset autoinflammatory disease. Nat Genet, 48(1), 67-73.

Disclosure of Interests: Kerstin Nott: None declared, Yvonne Glackin: None declared, Stephen D Marks Grant/research support from: chief investigator and principal investigator for pharma sponsored randomised controlled trials in children from Astellas and Novartis but receive no money personally as the income goes directly to our institutions., Paul Brogan Grant/research support from: SOBI, Novartis, Roche, Novimmune, Chemocentryx, Consultant for: Roche, SOBI, Speakers bureau: SOBI, Roche, Novartis, UCB, Sandrine Compeyrot-Lacassagne Grant/research support from: Abbvie

DOI: 10.1136/annrheumdis-2019-eular.224

\section{SAT0201 CARDIOVASCULAR EVENTS IN SYSTEMIC LUPUS ERYTHEMATOSUS (SLE): THE ROLE OF TRADITIONAL CARDIOVASCULAR RISK AND SLE-RELATED FACTORS}

Anna Maria Paglionico ${ }^{1}$, Valentina Varriano ${ }^{2}$, Luca Petricca ${ }^{1}$, Clara DI Mario ${ }^{2}$, Maria Rita Gigante ${ }^{1}$, Giacomo Tanti ${ }^{2}$, Barbara Tolusso ${ }^{1}$, Gianfranco Ferraccioli ${ }^{2}$, Elisa Gremese ${ }^{1,2}$. ${ }^{1}$ Fondazione Policlinico Universitario A. Gemelli IRCCS, Division of Rheumatology, Rome, Italy, ${ }^{2}$ Università Cattolica del Sacro Cuore, Division of Rheumatology, Rome, Italy

Background: Patients with SLE may have an increased risk of cardiovascular (CV) events due to the contribution of disease-related factors. Objectives: to determine the prognostic role of traditional CV risk factors and SLE-related factors in the assessment of the risk of $\mathrm{CV}$ events development in a cohort of patients affected by SLE.

Methods: Two hundred and sixty two consecutive SLE patients (age 42.9 \pm 14.5 years, $89 \%$ female, disease duration $11.5 \pm 8.2$ years) have been evaluated, 240 (92\%) with articular, $226(86 \%)$ with cutaneous, 167 $(64 \%)$ with hematological, 61 (23\%) with serositis involvement respectively and $86(33 \%)$ with lupus nephritis (LN) and $105(40 \%)$ with neuropsychiatric SLE (NPSLE). The follow-up data were collected and information on traditional CV risk factors (age, sex, diabetes, smoking, arterial hypertension, dyslipidemia), disease-specific parameters (SLEDAI-2K, chronic steroid therapy, current antimalarial and other immunosuppressive therapy) and autoantibody profile (ANA, anti-SSa/Ro, anti-SSb/La, IgA and IgM Rheumatoid factor (RF), complement reduction, anticardiolipin (ACLA), antibeta2glicoprotein 1 (antiß2GP1), lupus anticoagulant (LAC)) were analyzed for each patient. As CV manifestations, acute cardiac and cerebrovascular ischemic events and chronic ischemic heart disease were considered.

Results: Twenty-seven SLE patients (10.3\%) experienced CV events during the follow-up period with a significantly higher rate of male sex $(24 \%$ in males vs $8.6 \%$ in females, $\mathrm{p}=0.01$ ) among the considered demographical parameters. Among those patients, $10(37 \%)$ presented cerebrovascular accidents, 6 (22\%) acute cardiac ischemic events, 7 (26\%) chronic ischemic heart disease and $4(15 \%)$ both cardiac and cerebrovascular events during the follow up period. In particular, SLE patients who experienced $\mathrm{CV}$ events during the follow up were older at disease onset than patients who did not experience CV events during the follow-up (42.2 \pm 19.4 vs $29.8 \pm 13.1$ years, $p<0.001)$. Considering the traditional CVrelated risk factors, among the SLE cohort, patients who experienced CV events during the follow-up were more likely having concomitant dyslipidemia $(p=0.03)$, diabetes mellitus $(p=0.01)$ and arterial hypertension $(p<0.001)$ compared to SLE patients who did not experience CV events. Considering the disease-related parameters, no significant association between $\mathrm{CV}$ events development and ANA, anti-SSa/Ro, anti-SSB/La positivity and complement reduction was found $(p>0.05)$ despite SLE patients who experienced $\mathrm{CV}$ events during the follow-up were more likely with concomitant neurological involvement $(\mathrm{p}=0.002)$ and ongoing chronic corticosteroid therapy $(p=0.03)$ compared to SLE patients who did not experience CV events.

Finally, considering the antiphospholipid antibodies (aPL) profile, SLE patients who experienced $\mathrm{CV}$ events during the follow-up were more likely positive for antiß2GP1 ( $p<0.0001)$, ACLA $(p<0.0001)$ and LAC ( $p$ $<0.0001)$ compared to SLE patients who did not experience CV events. In addition, multivariate analysis revealed that, aPL positivity arose as an independent risk factor associated with CV events development in SLE patients contingently to the number of aPL positivities (single aPL positivity, OR 4.52 (0.97-21.18); double aPL positivity, OR 23.95 (4.39-130.76) triple APL positivity, OR 34.01 (7.64-151.40)).

Conclusion: in SLE patients, aPL positivity significantly increases the risk of CV events development regardless to the traditional CV risk factors contingently to the number of aPL positivities.

\begin{tabular}{|l|c|}
\hline Variable & polyautoimmunity, $(\mathrm{n}=501)$ \\
\hline Sex (female), $\mathrm{n}(\%)$ & $473(94.4)$ \\
\hline Age $>50$ years, $\mathrm{n}(\%)$ & $134(15.4)$ \\
\hline Raynaud's phenomenon, $\mathrm{n}(\%)$ & $226(45.8)$ \\
\hline Lupus Nephritis, $\mathrm{n}(\%)$ & $131(26.5)$ \\
\hline Pulmonary fibrosis, n (\%) & $25(5.0)$ \\
\hline ANA+, n (\%) & $497(99.0)$ \\
\hline Anti-RNP, n (\%) & $164(34.1)$ \\
\hline Methotrexate, $\mathrm{n}(\%)$ & $120(24.7)$ \\
\hline Hydroxychloroquine, $\mathrm{n}(\%)$ & $369(76.7)$ \\
\hline
\end{tabular}

\section{REFERENCE}

[1] Boulos D, Koelmeyer RL, Morand EF and Hoi AY, Lupus Science \& Medicine, 2017

Disclosure of Interests: Anna Maria Paglionico: None declared, Valentina Varriano: None declared, Luca Petricca: None declared, Clara Di Mario: None declared, Maria Rita Gigante: None declared, Giacomo Tanti: None declared, Barbara Tolusso: None declared, Gianfranco Ferraccioli Speakers bureau: BMS, Roche, Elisa Gremese Consultant for: AbbVie, BMS Celgene, Janssen, Lilly, MSD, Novartis, Sanofi, UCB, Roche, and Pfizer, Speakers bureau: BMS, Speakers bureau: Roche, Speakers bureau: AbbVie, BMS, Celgene, Janssen, Lilly, MSD, Novartis, Sanofi, UCB, Roche, and Pfizer

DOI: 10.1136/annrheumdis-2019-eular.7767

\section{SAT0202 EVALUATION OF LEFT ATRIAL MYOCARDIAL DEFORMATION AS MARKER OF SUBCLINICAL DAMAGE IN PATIENT WITH SYSTEMIC LUPUS ERYTHEMATOSUS}

Silvia Perez-Topete ${ }^{1}$, Tomas Miranda-Aquino ${ }^{2}$, Jorge Hernandez-del Rio ${ }^{2}$ Sergio Gutierrez-Ureña ${ }^{1}$, Gloria Martinez-Bonilla ${ }^{1}$, Veronica Gonzalez-Diaz ${ }^{1}$, Sergio Cerpa-Cruz ${ }^{1}{ }^{1}$ Civil Hospital Fray Antonio Alcalde, Rheumatology, Guadalajara, Mexico; ${ }^{2}$ Civil Hospital Fray Antonio Alcalde, Cardiology, Guadalajara, Mexico

Background: The left ventricle diastolic dysfunction (LVDD) may be the only manifestation of cardiac involvement in patients with systemic lupus erythematosus (SLE), preceding systolic dysfunction. The myocardial deformation of left atrium (LA) through the evaluation of LA global longitudinal strain (LALS) may be useful in assessing diastolic function since the lower the LALS the worse is the diastolic function.

Objectives: The main objective of this study was to evaluate the LA function through myocardial deformation by strain and strain rate derived from speckle tracking echocardiography in patient with SLE without any cardiovascular symptoms and compare with Control Group (CG). To compare LA strain of patients with active, inactive SLE disease and contro group and determinate the independent factors associated with depressed LALS.

Methods: A cross sectional study was performed. Fifty patient that fulfilled 2012 SLICC classification criteria for SLE were included and they were compared with fifty age- and gender -matched healthy subjects as contro group. Myocardial deformation was measured by transthoracic 